\title{
Land-use and the conservation of Sharpe's Longclaw Macronyx sharpei in central Kenya
}

\author{
MUCHANE MUCHAI, LEON BENNUN, LUC LENS, MATTHEW \\ RAYMENT and GIOVANNA PISANO
}

\section{Summary}

The highland grasslands of central Kenya hold a suite of restricted-range bird species, including several of global conservation concern. These grasslands occur almost entirely on private land with no formal protection, and have received little conservation attention. This paper describes land-use change on the Kinangop Plateau, Kenya, and considers the implications for grassland bird species, especially Sharpe's Longclaw Macronyx sharpei. The Kinangop Plateau is an area of montane grassland east of the Rift Valley, used primarily for dairy farming since human settlement in 1964. However, dairy farming (which retains grassland as pasture) has given way to other forms of land-use, especially cultivation of crops. In March 1996, a questionnaire was administered to 50 landowners to investigate community attitudes towards birds and their conservation, the extent of present land-use changes and likely future land-use patterns. The mean acreage of landholding was decreasing, and more grassland was rapidly being converted into cultivated land, with $3.2 \%$ being ploughed up during the six months from November 1995 to May 1996. Farmers expressed a preference for crop farming (66\%) over livestock farming $(26 \%)$ or other land uses. Thirty-two per cent expressed a positive attitude, and $60 \%$ were indifferent, towards birds. Most $(76 \%)$ were not aware of biodiversity values or conservation. Though $64 \%$ were aware of declining bird populations around them, $82 \%$ of this group did not realize that their activities might be contributing to this decline. Sixty-eight per cent of landowners planned to convert all or part of their grassland holdings. Although landowners' interests seemed generally incompatible with grassland conservation, a substantial proportion $(44 \%)$ were prepared to consider opportunities to enhance the area's conservation value. An informal follow-up survey in March 1999 concluded that prospects for the dairy industry and for grassland habitats on Kinangop were not as bleak as the initial survey suggested, but confirmed the delicate conservation status of Sharpe's Longclaw and its habitat. We suggest a variety of actions that might help to secure the future of Sharpe's Longclaw while promoting sustainable agricultural development on Kinangop, and propose several topics where further research is needed. Species such as Sharpe's Longclaw will only survive if we can develop ways of managing their habitats in a manner that is consistent, rather than in conflict, with the needs of the agricultural community.

\section{Introduction}

The central and western highland grasslands of Kenya, extending from the slopes of Mount Elgon east to both sides of the Rift Valley and across the Kinangop 
Plateau to Mount Kenya, form part of the Kenyan Mountains Endemic Bird Area (Stattersfield et al. 1998). This EBA includes two Important Bird Areas listed primarily for their grassland species: the Mau Narok/Molo Grasslands and the Kinangop Grasslands (Bennun and Njoroge 1999). Both these areas of grassland are under enormous pressure from the increasing human population. Grassland on Kinangop Plateau is dominated by extensively modified grazing pasture, but is being converted to arable crops, built development and afforestation, and fragmented by subdivision (Bennun and Njoroge 1999). The human population on the plateau has been increasing both through intrinsic growth and by immigration from other, still more densely populated, parts of Kenya. The population of Kinangop division of Nyandarua district grew at an average rate of $4 \%$ per year between 1989 and 1997, when it averaged 141 persons per $\mathrm{km}^{2}$ (Republic of Kenya undated). This increase in human pressure has brought environmental problems, and threatens grassland habitats and the birds that depend on them (Lens et al. 2000).

The biodiversity value of this highland grassland is not fully understood, but it is known to support four restricted-range bird species: Sharpe's Longclaw Macronyx sharpei (endemic to Kenya), Aberdare Cisticola Cisticola aberdare (endemic to Kenya), Hunter's Cisticola Cisticola hunteri (endemic to Kenya and northern Tanzania) and Jackson's Widow-bird Euplectes jacksoni (endemic to Kenya and northern Tanzania) (ICBP 1992, Stattersfield et al. 1998). Sharpe's Longclaw is listed as globally Vulnerable, Aberdare Cisticola as Endangered and Jackson's Widowbird as globally Near-threatened (BirdLife International 2000). Unlike the cisticola and the widowbird, there are no recent records of Sharpe's Longclaw from protected areas. Old sightings exist from Mt Kenya, Mt Elgon and the Aberdares National Parks, but its current status is uncertain: it may be scarce, very local or an occasional visitor. The survival of this species therefore appears to depend on the privately owned grasslands on each side of the rift valley.

Studies show that Sharpe's Longclaw occurs only in natural grassland habitats, favouring areas of open short grass intermixed with tussocks (Lens et al. 2000, Muchai et al. in press). It avoids woodlots, weedy and cultivated areas, and reseeded grass monocultures. As well as direct habitat loss, fragmentation of grasslands negatively affects this species (Lens et al. 2001). Before 1964, the Kinangop Plateau was an extensive, almost treeless grassland habitat, but after human settlement, dairy farming became the predominant land-use on the plateau. However, in recent years natural grassland has increasingly been converted to fast-growing exotic trees (mainly Eucalyptus) or crops such as wheat, barley, pyrethrum, maize, beans, potatoes and cabbages, or has been ploughed and reseeded with grass to support higher densities of livestock (mainly cattle and sheep) (Muchai 1998, Bennun and Njoroge 1999). Remaining areas of natural grassland have often been degraded by overgrazing and removal of perennial tussock grass species (such as Andropogon amethystinus, Cymbopogon nardus, Digitaria diagonalis, Eleusine jaegeni, Hyparrhenia hirta, H. tamba and Pennisetum hohenackeri), which are siliceous and unpalatable to livestock. Farmers occasionally burn grassland plots in order to control tussock species, but it is unknown how the present fire regime compares to the natural incidence of burning.

Between November 1995 and May 1996, MM, LAB and LL investigated landuse and community attitudes towards birds and their conservation on the Kinan- 
gop Plateau, around the trading centre of Heni, as part of a wider ecological study, focusing especially on Sharpe's Longclaw, the extent of present land-use changes and the likely future land-use patterns. In March 1999 this survey was followed up (by MR and GP) around the trading centre of Murungaru, using informal interviews with members of the farming community to investigate further the causes of these trends.

\section{The study area}

The Kinangop Plateau (Nyandarua district, central Kenya: $0^{\circ} 32^{\prime}-46^{\prime} \mathrm{S} ; 36^{\circ} 29^{\prime}-$ $38^{\prime} \mathrm{E}$ ) is a stretch of montane grassland at 2,400-3,000 m altitude located between the Aberdare mountains (the easternmost scarp of the Gregory Rift Valley) and the rift floor (Figure 1). Descriptions of vegetation, soils and climate can be found elsewhere (Bennun and Njoroge 1999, Lens et al. 2000). The area is inhabited by the agriculturally based Kikuyu people, whose livelihood revolves around small-scale crop farming (mainly wheat, barley, pyrethrum, maize, beans, potatoes) and livestock rearing (cattle, sheep, goats and donkeys). Woodlots are afforested with Eucalyptus and other fast-growing, exotic trees.

\section{Methods}

Heni survey, 1996

A questionnaire was designed to assess the attitudes of local communities towards birds and their conservation, and to collect information and views about land-use patterns (see Appendix). The questionnaire contained both closed- and open-ended questions and collected general information about the respondent and his/her attitudes to birds and conservation; information on Sharpe's Longclaw and the historical and current distributions of Kinangop grassland birds; details of utilization of grasslands by the community; views about the threats posed by people to the grassland resource; and information on the respondent's own past, present and future land-use plans.

Our study area was centred on the trading centre of Heni, in the west-central part of the plateau, and contained around 200 farms. We used a systematic sampling technique to interview every third farmer in the study area. The survey was targeted at landowners only. A total of 50 local landowners (aged between 18 and 82 years) were surveyed, using a combination of self-fill questionnaires and face-to-face interviews. The assessment took eight days, from 21 to $28 \mathrm{March}$ 1996. Land-use patterns in the study area were also assessed and monitored from November 1995 to May 1996, during an ecological study of Sharpe's Longclaw (Muchai et al., in press).

\section{Murungaru survey, 1999}

A follow-up survey was conducted on 5 and 6 March 1999 by a joint team from the Royal Society for the Protection of Birds and Nature Kenya. The aim was to investigate further the causes of the land-use changes revealed by the Heni study, through a series of informal interviews with local farmers, landowners and agricultural traders, with a view to establishing more detailed socio-economic research in the area in future. The survey was centred on the town of Murungaru, 


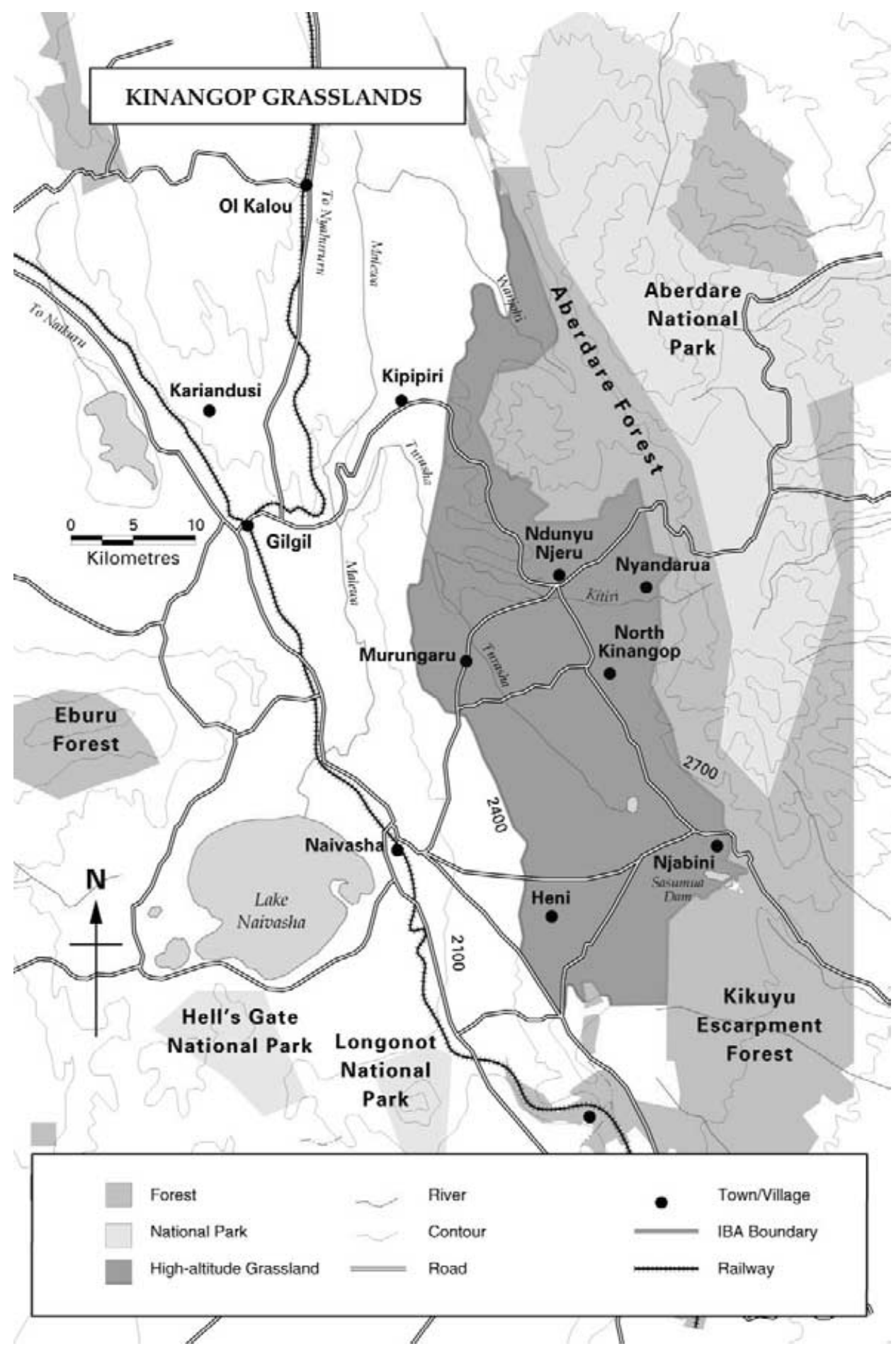

Figure 1. Map showing the study area in the Kinangop grasslands, Kenya. 
some $20 \mathrm{~km}$ to the north of Heni. This area was selected because it is the headquarters of a local conservation group, the Friends of Kinangop Plateau.

The economics of milk and crop production were examined in more detail than in the Heni survey. Farmers were asked a variety of questions about landuse changes, grassland management practices, milk and crop yields, stocking rates, the costs of crop and dairy production, and future expectations. Interviews with a milk trader and a dairy cooperative provided further information about the state of the milk market. Because of the small sample, the informal nature of the interviews and the difficulty of validating the results obtained, the results of the Murungaru survey need to be interpreted with some caution. Nevertheless, they provide a useful insight into the social and economic factors affecting landuse change in the Kinangop Plateau.

\section{Results}

Land in Kinangop is normally owned by men, who are considered the head of the household, and tend to make decisions about land-use. The distribution of respondents in the Heni survey was therefore biased towards men, and particularly older men; 37 respondents were male $(74 \%)$ and 13 female. Respondents by age class were: two 20 years old or less, five $21-30$, seven $31-40$, sixteen $41-50$, ten 51-60, seven 61-70 and three older than 70 years.

\section{Community attitude towards birds}

About three quarters $(76 \%)$ of respondents had no awareness of biodiversity conservation. The remainder usually had only a general awareness, and thought of conservation as something that took place solely in national parks or reserves. Nearly a third (32\%) liked birds for a variety of reasons, including their aesthetic beauty, songs, pest control benefits, intrinsic or moral value, their right to exist, because they are a creation of God, as indicators of seasonal change, or as traditional symbols of peace and happiness. All the adults interviewed thought it was childish to like birds. Eight per cent of respondents disliked birds on the grounds that they are crop pests, or because of the negative traditional beliefs attached to some birds, especially owls. The remaining $60 \%$ of respondents expressed no feeling for birds. Nearly two thirds $(64 \%)$ of respondents were aware that grassland birds were declining in the area, $4 \%$ were unaware and $32 \%$ were unsure. Of those who were aware of the decline, $18 \%$ agreed the decline could be due to their land-use activities, while the rest $(82 \%)$ had no idea why birds might have declined. Nearly a third (30\%) of respondents knew Sharpe's Longclaw. Of these, 92\% considered it to have no economic importance, while $4 \%$ thought it was beneficial as a biological pest control agent, and the remaining $4 \%$ thought of it as a nuisance. The last view was attributed to the general thinking that wild birds would transmit disease to domestic chickens reared under free-range systems in the study area. There appear to be no traditions connected to Sharpe's Longclaw, and people in this area do not eat wild birds.

Fifty-six per cent of respondents said they could not leave the grassland they owned uncleared for the sake of birds, although they did not mind the birds utilizing the area. Eight per cent said they would leave a portion uncleared for 
the birds' benefit, while $36 \%$ indicated that they would be prepared to leave a portion of grassland uncleared if they were compensated for doing so.

Land use and utilization of grassland by the local community

The livelihood of the Kikuyu community in and around the study area revolves around livestock rearing and small-scale cultivation of both subsistence and cash crops. Traditionally, the local economy has been dominated by dairy farming. However, the survey found that $66 \%$ of respondents now considered crop farming to be the most valuable local land-use. Livestock farming was considered more attractive by $26 \%$, woodlots by $6 \%$, and other uses by the remaining $2 \%$. Crop farming was favoured over livestock farming because of a drop in milk prices and late payment of dues to dairy farmers by the state dairy cooperative, Kenya Cooperative Creameries (KCC). Other factors increasingly favouring crops included the improvement of the road network by Nyandarua district council (making it easier to take crops to market), reduced incidence and duration of flooding, less frequent frosts, a ready market for crop produce in the surrounding towns, the ability to diversify by growing a variety of crops, and a reduced acreage per farm.

The 50 local landowners interviewed had a total of 571 ha of land with a mean of $11.4 \pm 12.4$ (S.D.) ha per household. Of these, grasslands (occurring as pasture) covered $62 \%$ of the area ( 353 ha) with a mean of $7 \pm 9.7$ (S.D.) ha per household. Crops covered 177 ha (31\%), woodlots 23 ha (4\%) and other uses 17 ha $(3 \%)$. Sixty-eight per cent of landowners had plans to clear their portion of grassland, either for crop farming $(76 \%)$, for pasture regeneration in order to remove the tussock grass species (16\%), or for conversion to woodlots (8\%). Eight per cent of respondents were undecided whether or not to clear grassland in future. Thirty-four per cent of the grassland within the study area (120 ha) was grazed but contained at least $20 \%$ tussock cover, approximating a 'natural' state. The rest $(66 \%)$ was significantly modified (heavily grazed, reseeded or weedy, and with tussocks making up less than $20 \%$ of its area.).

In general, the mean acreage of landholding was decreasing, and more grassland was being converted into cultivated land, degraded or fragmented. Between November 1995 and May 1996, 3.2\% of the grassland area in the study site was ploughed up, either for cultivation or reseeding. Many farmers had planted Eucalyptus saplings along their fences, and more woodlots were being established. In the absence of detailed historical records, we do not know for certain whether grassland conversion rates are falling or rising. However, as the human population is steadily increasing and the mean acreage of landholding is decreasing, it seems very likely that more grassland is being converted into cultivated land.

\section{Findings in Murungaru}

The Murungaru interviews gave a slightly more optimistic picture of the prospects for land-use change on Kinangop than the Heni study.

\section{Climate and land-use}

It was clear from the interviews that climatic variations have a significant impact on agriculture on Kinangop, and affect the economics of arable and dairy farm- 
ing. In the past, the relatively cool, damp climate, with frequent frosts and flooding, favoured dairy farming. Wet weather conditions favour grass growth, while flooding can lead to the destruction of crops. The El Niño effect brought heavy rainfall between March and May 1998, causing most crops to be lost.

Frost adversely affects both crops and grass, and usually leads to complete crop failure. Frost also kills many grasses, although some, especially tussock grasses, are frost-resistant. Frost and drought may lead to the death of livestock. At these times animals may eat tussock grass, seemingly unpalatable at other times, as a last resort. Some farmers on Kinangop grow wheat, despite advice from the Government that the area is too wet for wheat production.

\section{Land-use change}

The interviews with farmers in Murungaru suggested that, in current conditions, dairy farming is likely to remain the dominant enterprise. Most farmers are unwilling to convert all of their land to arable production as this brings significant risks of total crop failure. Thus while the 1990s saw the conversion of large areas of land from dairy to arable production, these changes occurred in order that dairy farmers could diversify to avoid over-reliance on a single enterprise. While some farmers expect this trend to continue, those we interviewed expected to retain some dairy farming, as it may be their only source of income if crops fail. Many crops are grown for subsistence or animal feed (especially maize), but some, especially potatoes, are grown for cash. A few farmers have tried growing flowers, encouraged by the profitability of flower growing around Lake Naivasha, although, given the poor communications on Kinangop, there must be doubts about the ability of these growers to reach high-value markets. Farmers' ability to transport produce has significant implications for land-use. The poor state of roads on Kinangop plateau, and the preponderance of bicycles as a means of transporting food, tend to favour dairy farming, which produces regular yields rather than large, irregular harvests.

While dairy farming has become less attractive in the last decade, largely as a result of milk marketing problems, it remains the preferred enterprise for many farmers, since it is less labour intensive and generally less difficult than arable farming on Kinangop. There are indications, therefore, that growth in the dairy sector might occur if the milk market became more attractive and reliable.

Further climate change could result in further changes in land-use, as crops would benefit from fewer frosts. Changes in rainfall are also important in influencing land-use. Only 1o $\mathrm{km}$ away from Kinangop, where there are no frosts, more maize is grown, but many farms also have dairy enterprises.

As a result of the scarcity of land, prices are high - estimated to average 180 ,000 Kenyan shillings per acre $(\$ 6,750 /$ ha) in March 1999, despite the apparent low profitability of agriculture. So-called ethnic clashes elsewhere in the Rift Valley seem to have driven up land prices in Kinangop in the late 1990s; but prices had settled back to around KSh 120,000 (\$4,500/ha) by mid-2001 (LAB, unpubl. data).

\section{Grassland management}

Farmers see tussock grasses as having some value in grassland systems because of their resistance to variations in climate. In case of drought, tussock may be 
cut, chopped and mixed with water and molasses to feed the animals. Apart from providing an emergency food resource, tussock is considered to be of no use in normal times and even a problem as it is unpalatable and difficult to digest, requiring heavy rumination, and exerting pressure on animals' teeth.

Some farmers have tried to introduce new grass species, but many have failed, as they are not as hardy as native species. Ploughing can be used to renew pastures and to suppress tussock grass, typically in a three-year rotation. Fertilizer is used, where farmers can afford it, to improve the productivity of grassland, so that it is able to support more cattle. Many dairy farmers would like to improve their pasture, but a lack of finance for fertilizer is often a problem. Some farmers who were forced to reduce stocking rates when the dairy market collapsed now have insufficient funds to invest in grassland improvement.

It is possible that a significant intensification of grassland management, including regular ploughing and application of fertilizer, would prevent tussocks becoming established, and could reduce the value of grassland habitats for species such as Sharpe's Longclaw. Ploughing grassland in a three-year rotation, for example, might not allow sufficient time for tussock to regenerate.

\section{Dairy yields and stocking rates}

Dairy cow yields are very variable according to season. The productivity of the cows themselves also varies between farms. Typical milk yields are around $2 \mathrm{~kg}$ per cow per milking in the dry season, and $6 \mathrm{~kg}$ per cow per milking in the wet season, with cows producing milk for an average of 6 months in the year.

Although cows are milked once in the morning and once in the evening, only the morning milk can be sold. Evening production is used for family consumption, or fed to livestock, as no refrigeration system is available and the quality of milk is too low to allow it to be sold the following morning. According to a dairy cooperative, farmers would benefit from the installation of refrigeration and processing facilities, to increase the quantity, quality and price of milk sold.

Stocking rates for dairy cows vary according to the quality of pasture. Good, improved pasture can hold one cow to 0.2 ha ( 0.5 acres), while poor pasture may have one cow to 1.6 ha (4 acres) or more. Around $20 \%$ of farmers have improved, high-yielding pasture. Many others would like to improve their pasture but are constrained by a lack of funds for fertilizer and other inputs. Some farmers also keep sheep.

\section{Dairy costs}

Dairy farming is much less labour intensive than crop farming, requiring one person per 3-4 cows per day. Other major expenses are supplementary feed and veterinary costs. During our visit, we collected some simple data on the costs and revenues of dairy enterprises. These suggested that current dairy yields would not enable most enterprises to cover their costs. We suspect that the data farmers gave us was an overestimate of the actual cost of the dairy enterprise, 
and that expenditure on items such as veterinary care in most cases is well below the theoretical requirement.

\section{Dairy marketing}

Kenya is not self-sufficient in milk products, and imports significant quantities of milk, mainly from South Africa as milk powder. Kenyan production experiences strong seasonal fluctuations, and Kenya is more self-sufficient in the wet season, when processors often have insufficient capacity to accept all of the milk produced. Milk producers agree to supply a given quantity of milk to processors, typically agreeing to provide a minimum amount in the dry season. Processors may place a limit on the quantity of milk they accept in the wet season, and may refuse to accept excess production.

The price of milk in March 1999 was 15 shillings (\$o.22) per kg. It tends to be higher (at around 19 shillings (\$0.29) per kg) during dry weather.

Until recently, milk marketing in Kenya was dominated by KCC, which had some success before financial difficulties caused its collapse in the early $1990 s$. Farmers' complete reliance on KCC meant that its collapse resulted in many of them not being paid for their milk. This was a major factor in driving farmers to grow crops to diversify their income. After the collapse of KCC, the milk market has been liberalized, and many new cooperatives have emerged.

Since liberalization, competition in milk marketing has increased. Milk buyers claim that this has brought better prices and more reliable payments for farmers, but some farmers complain that middlemen (buying from farmers and selling to processors) are unreliable, and that they cannot be certain of them remaining in business. One significant problem is that payments for milk are made in arrears, after it is tested for quality and microbiological content. Farmers continue to lack confidence in the milk marketing system. Other crops, such as potatoes, have the advantage in that payment is made in cash on inspection of the product.

Some farmers expect confidence in the milk marketing system to improve in the longer term as cooperatives become more established and reliable and begin to build a stronger reputation.

\section{Crop production}

Potatoes Farmers can attempt to grow two crops of potatoes per year during the two rainy seasons. However, potatoes have a failure rate of more than $50 \%$, as crops may be lost to frost, floods and drought. Potato prices vary significantly according to the weather, rising significantly at times of shortage. The main costs in growing potatoes are labour, plough hire, fertilizer and seed. The market for potatoes in Kenya is growing, and there are opportunities for farmers to supply increasing markets in nearby towns such as Naivasha. Potatoes are also grown for subsistence.

Maize Maize is normally grown as a staple rather than a cash crop, and yields one crop per year. The failure rate is even higher than that for potatoes, with only a $25-35 \%$ chance of a successful crop. Following a recent crash in the maize price, the Government intervened in the market, buying maize to support the price. Costs are similar for potato crops, but more fertilizer is usually applied. 


\section{Conclusions from the Murungaru survey}

The main findings of the Murungaru interviews were that:

- In spite of recent climatic changes, frosts and floods still result in a high risk of crop failure.

- As a result, farmers tend to be reluctant to convert completely to crop production and prefer to retain a mixed farming enterprise.

- While farmers remained cautious, there was slightly greater optimism about the future market prospects for milk.

- Other factors, such as labour and transport requirements, favour dairy farming, which produces more regular yields than crop farming.

Nevertheless, the interviews did confirm the delicate conservation status of Sharpe's Longclaw and other grassland bird species, since:

- Clearance of grassland, while not yet appearing to threaten the whole area, is continuing.

- The future of dairy farming is sensitive to confidence in the milk market.

- Further climatic change could result in further changes in land-use, especially if frosts continue to become less frequent.

- Further population growth is likely to reduce farm size further, resulting in the conversion and fragmentation of grassland habitats.

- Some of the farmers interviewed expressed an intention to improve grasslands by ploughing and fertilizing them (although financial constraints limit their ability to purchase fertilizers).

\section{Discussion}

Kinangop Plateau supports a large proportion of the remaining world population of Sharpe's Longclaw. The survival of this species depends on the maintenance of traditional extensive grassland habitats, consisting of native grassland species and with a variable structure of short grass and well-developed tussocks (Lens et al. 2000). Sharpe's Longclaw is threatened by conversion of grassland to arable cropping (Muchai et al. in press) and subdivision, fragmentation and improvement of remaining grassland units (Lens et al. 2000). Ndang'ang'a et al. (in press) show that the number of separate farms on the plateau doubled between 1984 and 1994. In this period the area covered by large farms (more than $30 \mathrm{ha}$ ), which are most likely to contain suitable longclaw habitat, decreased from $18 \%$ to $9 \%$ of the total. Ndang'ang'a et al. predict that by 2010 the current area under tussock grassland will have halved again, to cover only $12-20 \%$ of the plateau. Furthermore, almost all this tussock grassland will be on small farms (2-10 ha), which provide a poor prospect for longclaws.

Continuing population growth on Kinangop threatens to reduce further the grassland habitats on which Sharpe's Longclaw depends. Land in the area is predominantly privately owned, and most land-use decisions are taken by male members of the farming family. The future of the species may depend on conservation action to influence land-use and land management in the area.

Our surveys show that the key to conservation of Sharpe's Longclaw is to slow, and eventually reverse, the conversion of grasslands to crop farming. In 
similar situations elsewhere in the world several approaches have been used to influence land use (Groombridge 1992). However, these may not be workable in the case of Kinangop. Outside national parks, there is very little government conservation effort in Kenya. Regulatory restriction of land-use is probably not an option, given the current system of property rights and the social and economic problems facing Kinangop. Incentive measures, such as agri-environment schemes, can provide an effective means of meeting conservation objectives while securing farm incomes. However, they are very expensive to implement and the resources are unlikely to be available here. The high cost of land also makes land purchase, to secure the conservation of particular areas of grassland, an impractical measure.

The greatest potential appears to lie in measures to enhance the viability of the dairy sector, with the aim of making dairy farming once again a more attractive proposition than crop farming. For example, development of milk refrigeration facilities could increase the proportion of marketable milk and reduce wastage. Investment in a milk processing plant - to convert milk to storable products such as ultra-heat treated packaged milk, powdered milk, butter and cheese - would help to address the problem of surplus production, which causes the milk price to crash during rainy weather.

Any such developments need to be considered in relation to the threat of possible intensification of dairy farming. This issue could be addressed by making access to these facilities conditional on conservation-friendly grassland management practices. Demonstration of sound grassland management, either on a reserve or using land belonging to sympathetic dairy farmers, would therefore be an important part of this approach. This could include setting up high-yield 'kitchen gardens' run using organic techniques, allowing food crops to be grown for home consumption using only a relatively small area of land.

In parallel with these measures, ecotourism initiatives could help to enhance the returns that farmers and local communities derive from conservation-friendly grassland management. This would require the development of suitable tourism infrastructure and marketing. Awareness raising, advice and training initiatives could help to promote understanding of Kinangop's wildlife and its habitat among farmers and local communities. This might take a variety of forms such as posters, advisory leaflets, training sessions for dairy farmers, and visits to schools and community groups;

Some progress has been made in pursuing these ideas. The Friends of Kinangop Plateau (FKP) is a group established to promote the conservation of characteristic grassland birds and the wider environment, by raising awareness among farmers and the general public. It is involved in an education programme for local schools to raise awareness of the birds' habitat requirements and the links between dairy farming and grassland management. The Friends of Kinangop are also trying to convince people that the rare birds of Kinangop offer potential economic opportunities through ecotourism. The group now has three branches in different parts of the plateau, in the towns of Njabini, Engineer and Murungaru. It has a wide spread of ages among its membership, and aims to conserve Kinangop for current and future generations.

In conjunction with the Friends of Kinangop and a local dairy cooperative, Nature Kenya (the BirdLife International Partner in Kenya) has submitted a pro- 
posal to the European Union's Community Development Trust Fund in Kenya for funding a milk refrigeration facility. If the facility is built, a small levy on each litre of milk will go to support the conservation activities of FKP. Farmers joining the cooperative and using the facility will also need to meet minimal standards of environmentally friendly land management, including the maintenance of pasture with tussock grasses.

Future action to conserve Sharpe's Longclaw and other grassland species would benefit from further research into the factors driving land-use change on the Kinangop Plateau, and their ecological results. This would involve socioeconomic, environmental and ecological studies as outlined below.

\section{Socio-economic studies}

- The size, distribution and structure of farms, areas of crops and grassland, and recent trends caused by population change; this would help to improve understanding of trends in habitat fragmentation. A start has been made in the recent study by Ndang'ang'a et al. (in press).

- The various cooperatives and farmers' organisations on Kinangop, and the numbers of members they represent; this would help to identify key targets for future conservation effort.

- The economics of farming on Kinangop; to improve our understanding of the forces driving land-use change.

- The potential for ecotourism on the Kinangop plateau.

- Potential sources of funding for conservation and development projects focusing on the dairy sector.

\section{Environmental studies}

- The factors causing climate change on the plateau, including those related to microclimate and those reflecting wider climate changes; to improve understanding of possible future changes and their likely effects on agricultural land-use.

\section{Ecological studies}

- The effect of different grassland management practices on habitat quality, and especially the conditions needed to maintain tussock grass and the effects of different grassland 'improvement' practices (such as fertilizer applications, ploughing, reseeding) and stocking rates on grassland structure.

- The effects of fragmentation of grassland habitats on Sharpe's Longclaw and other species - in particular, the relationship between the spatial configuration of the landscape and breeding success, natal dispersal and individual movements (Lens et al. 2000). There may be patches of 'source' and 'sink' habitats for longclaws (Pulliam and Danielson 1991) and it is important to identify these so as to focus conservation attention on the appropriate sites. 
Agriculture on the Kinangop Plateau is struggling to feed an increasing population. The challenge is to identify means of developing traditional farming systems sustainably, in order to enhance output while safeguarding their biodiversity value. Species such as Sharpe's Longclaw will only survive if we can develop ways of managing their habitats in a manner which is consistent, rather than in conflict with, the needs of the agricultural community.

\section{Acknowledgements}

We wish to thank Anthony Mwaura and Stephen Mungai, who assisted in data collection during the Heni survey; the Friends of Kinangop Plateau, who participated in the Murungaru survey; and Paul Matiku and Solomon Mwangi from Nature Kenya, who coordinated the Murungaru visit by MR and GP. The financial support of the Royal Society for the Protection of Birds and Moi University and the material support of the Department of Ornithology, National Museums of Kenya, is gratefully acknowledged. The Heni survey was conducted on private land owned by the local farmers, to whom we should like to extend our thanks. We also thank W.R.J. Dean, David Allan and Seb Buckton for comments that helped to improve the paper.

\section{References}

Bennun, L. and Njoroge, P. (1999) Important Bird Areas in Kenya. Nairobi: Nature Kenya. BirdLife International (2000) Threatened birds of the world. Cambridge, U.K. and Barcelona: BirdLife International and Lynx Edicions.

Groombridge, B., ed. (1992) Global biodiversity: Status of the Earth's living resources. New York: Chapman and Hall.

ICBP (1992) Putting biodiversity on the map: priority areas for global conservation. Cambridge, U.K.: ICBP.

Lens, L., Muchai, M., Bennun, L. and Duchateau, L. (2000) How grassland fragmentation and change in land-use affect Sharpe's Longclaw, Macronyx sharpei, a Kenya highland endemic. Ostrich 71: 300-303.

Lens, L., Bennun, L.A. and Duchateau, L. (2001) Landscape variables affect the density of Sharpe's longclaw Macronyx sharpei, a montane grassland specialist. Ibis 143: 674676.

Muchai, M. (1998) Some aspects of the conservation biology of Sharpe's Longclaw (Macronyx sharpei Jackson, 1904), a Kenya grassland endemic bird. Unpublished MSc thesis, Moi University, Eldoret.

Muchai, M., Lens, L. and Bennun, L. (2002) Habitat selection and conservation of Sharpe's Longclaw (Macronyx sharpei), a threatened Kenyan grassland endemic. Biol. Conserv. 105: 271-277.

Ndang'ang'a, P. K., du Plessis, M. A., Ryan, P. G. and Bennun, L. (in press) A landscape model of grassland decline in Kinangop Plateau, Kenya: implications for conservation of Sharpe's Longclaw (Macronyx sharpei). Biol. Conserv.

Pulliam, H. R., and Danielson, B. J. 1991. Sources, sinks, and habitat selection: a landscape perspective on population dynamics. Am. Nat. 137: 550-566.

Republic of Kenya (undated) Nyandarua District Development Plan, 1997-2001. Nairobi: Government Printer.

Stattersfield, A. J., Crosby, M. J., Long, A. J. and Wege, D. C. (1998) Endemic bird areas of the world. Priorities for conservation. Cambridge, U.K.: BirdLife International. 


\section{MUCHANE MUCHAI ${ }^{1}$, LEON BENNUN ${ }^{2}$}

Department of Ornithology, National Museums of Kenya, PO Box 40658 Nairobi, Kenya

\section{LUC LENS}

Department of Ornithology, National Museums of Kenya and Laboratory of Animal Ecology, Department of Biology, University of Antwerp, UIA, Universiteitsplein 1, B-2610 Wilrijk, Belgium.

\section{MATTHEW RAYMENT, ${ }^{3}$ GIOVANNA PISANO}

Royal Society for the Protection of Birds, The Lodge, Sandy, Bedfordshire, SG19 2DL, UK. E-mail matthew.rayment@rspb.org.uk

${ }^{1}$ Now at Percy FitzPatrick Institute of African Ornithology, University of Cape Town, Rondebosch 7701, Cape Town, South Africa.

${ }^{2}$ Now at Birdlife International, Wellbrook Court, Girton Road, Cambridge $\mathrm{CB}_{3}$ oNA, UK.

${ }^{3}$ Author for correspondence.

Received 5 July 2001; revision accepted 14 January 2002

\section{Appendix. Questionnaire used in a survey of land-use practices and attitudes towards conservation in Heni, Kinangop plateau, Kenya, 1996. (English transla- tion of questionnaire administered in Kikuyu.)}

\section{A. General information on the respondent}

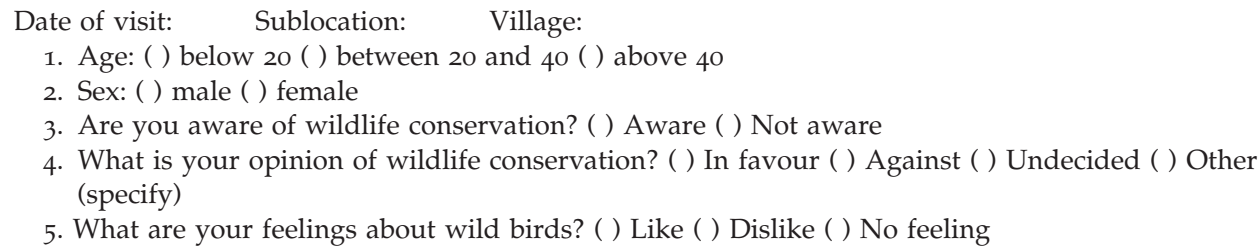

\section{B. Information on Sharpe's Longclaw}

6a. Do you know of birds called Sharpe's Longclaw? (tuthonjo twa weru-ini) ( ) Yes ( ) No

6b. Do you know that this species risks being wiped off the earth? ( ) Yes ( ) No

7a. Does Sharpe's Longclaw play any traditional role among the people of this area? ( ) Yes ( ) No If yes, specify:

7b. Do you know of any traditions prohibiting the killing of this bird? ( ) Yes ( ) No If yes, give reasons for their protection:

8. Do people hunt this bird around here? ( ) Yes ( ) No If yes, rank the reasons why they hunt the bird: ( ) Food ( ) Sale ( ) Any other (specify)

9. According to you, what is the economic importance/contribution of Sharpe's Longclaw in your area?

9. ( ) Beneficial as a biological pest control ( ) A crop pest ( ) General nuisance ( ) Not aware of any ( ) Other (specify) 


\section{C. (i) Use of grasslands by local community}

10. Around this area, the land is mostly used for: ( ) Livestock ( ) Crop farming ( ) Forest ( ) Other (specify)

11. Of what use is grass in the grasslands to people around here? ( ) Thatching ( ) Sale ( ) Other (specify)

12. What domestic animals are grazed in the grasslands around here? ( ) Cattle ( ) Goats ( ) Sheep ( ) Other (specify)

13a. How many acres of land do you own?

(i) What is your intended use of this land?

(ii) Of your land, what proportion is grassland?

(iii) Do you have plans to clear this portion in future? ( ) Yes ( ) No

If yes, for what reasons?

13b. Sharpe's Longclaw is a grassland bird. If you have a piece of grassland, would you leave it uncleared for the sake of birds? ( ) No ( ) Yes ( ) Other (specify)

C (ii) Threats posed by local people to the grassland resource

14. Please rank the most common causes for the clearing of grasslands by people around here:

( ) To create more agricultural land

( ) To create more places for settlement

( ) To allow for more industrial development

( ) Other (specify)

15. Please rank the comparative advantage, in terms of economic values, of the following land-use alternatives in your home area: ( ) Crop farms ( ) Forest ( ) Pasture

16. How do people around here control bird pests that might destroy crops? ( ) Poison ( ) Traps ( ) Scarecrows ( ) Other (specify)

\section{Historical and current distribution of Sharpe's Longclaw}

17a. Are you aware of any birds that were once found in the nearby grasslands and now have declined or disappeared? ( ) Yes ( ) No ( ) Not sure

If yes, please name the declining or extinct birds:

How long is it since you last saw these declining or extinct birds? ( ) Less than 5 years ( ) Between 5 and 10 years ( ) Between 10 and 15 years ( ) Over 15 years

17b. What do you think is the cause of decline or disappearance for these birds?

18. How was the vegetation composition/structure when you first settled here? ( ) Wild grassland ( ) Wild forest ( ) Same as today ( ) Other (specify)

18. Are you aware of any grassland areas that have been completely cleared? ( ) Yes ( ) No ( ) Not sure

If yes, please name the area cleared:

19. Are you aware of any birds that have been affected by grassland clearance? ( ) Yes ( ) No ( ) Not sure

If yes, please name the birds: 
